\title{
ÁAirman
}

Jurnal Teknik dan Keselamatan Transportasi

\section{Rancangan Model Speed Brake Flaps Tipe Clamsheel sebagai Alat Peraga di Prodi Teknik Pesawat Udara Sekolah Tinggi Penerbangan Indonesia}

\section{Design of Speed Brake Flaps Type Clamshell Mode as a Figure Tool in the Aircraft Engineering Indonesian Civil Aviation Institute}

\author{
Hendri Louis Latif ${ }^{1}$, Wahyu Kuntoaji ${ }^{2}$ \\ louishendri7@gmail.com,wahyukuntoaji@gmail.com
}

Politeknik Penerbangan Makassar

\begin{abstract}
ABSTRAK
Melihat perkembangan tekonologi didunia penerbangan pada saat ini dirasakan sangat pesat, hal ini juga harus diiringi dengan alat-alat praktik yang harus mengikuti perkembangan teknologi tersebut untuk menunjang kegiatan belajar mengajar. Untuk menunjang kegiatan belajar mengajar maka dari itu penulis bermaksud untuk membuat permodelan alat peraga simulasi speed brake flaps yang terdapat pada pesawat terbang, dan mengenalkan sistim speed brake flaps yang terdapat pada pesawat terbang dan dapat pula memberikan gambaran secara umum mengenai sistim flight control mengenai speed brake flaps sehingga proses pengajaran dapat berhasil sesuai dengan tujuan dari syllabus yaitu siswa memiliki kemampuan untuk dapat memahami prinsip dasar dari struktur pesawat terbang serta memiliki kemampuan dasar melakukan perawatan, karena selama ini siswa hanya dapat membayangkan tidak pernah melihat secara langsung alat yang dipelajari. seed brake merupakan jenis flight control surface yang digunakan pada pesawat untuk meningkatkan gaya hambat (drag). Simulasi speed brake ini memberikan gambaran mengenai pengoperasian dan mekanisme kerja sebuah speed brake. Rancangan ini dibuat dengan sistim yang sederhana untuk memudahkan pengoperasian. Dalam perancangang, metode yang digunakan adalah Metode pustaka menggunakan buku - buku literatur dan metode eksperimen. Karena sifatnya hanya sebagai alat peraga, maka tekanan hidrolik yang dibutuhkan adalah rendah. Tekanan hidrolik yang digunakan untuk mengoperasikan rancangan alat peraga ini adalah 90 psi dengan beban pada sistim mekanikal sebesar 160,83 lbs. Sumber arus listrik yang digunakan untuk mengoperasikan rancangan alat peraga ini adalah 220V AC untuk menghidupkan motor listrik dengan daya 1 HP sehingga memutar pompa hidrolik tipe gear yang menghasilkan fluida bertekanan untuk pengoperasian. Dibutuhkan daya sebesar 766 Watt untuk mengoperasikan rancangan alat peraga ini.
\end{abstract}

Kata kunci: speed brake flap; alat peraga; piston engine

\section{ABSTRACT}

Seeing the development of technology in the world of aviation at this time felt very rapidly, this must also be accompanied by practical tools that must follow the development of these technologies to support teaching and learning activities. To support teaching and learning activities, therefore the author intends to make modeling of teaching aids speed brake flaps found on an aircraft, and introducing the 
speed brake flaps system found on an aircraft and can also provide an overview of the flight control system regarding speed brake flaps so that the teaching process can be successful in accordance with the objectives of the syllabus, namely students have the ability to can understand the basic principles of aircraft structure and have the basic ability to perform maintenance, because so far students can only imagine never seeing directly the tools being learned. seed brake is a type of flight control surface used on aircraft to increase drag (drag). This speed brake simulation provides an overview of the operation and mechanism of action of a speed brake. This design was made with a simple system to facilitate operation. In the designer, the method used is the library method using literature books and experimental methods. Because it is only as a prop, the hydraulic pressure needed is low. The hydraulic pressure used to operate the design of this trainer is 90 psi with a load on the mechanical system of $160.83 \mathrm{lbs}$. The electric current source used to operate the design of this teaching aid is $220 \mathrm{~V}$ AC to start an electric motor with $1 \mathrm{HP}$ power so that it rotates the gear type hydraulic pump which produces pressurized fluid for operation. It takes a power of 766 Watt to operate the design of these Trainer.

Keywords: speed brake; props; engine piston

\section{PENDAhULUAN}

Kemajuan teknologi khususnya di bidang perhubungan udara mendorong Perguruan Tinggi dibidang ini untuk menyediakan sarana dan prasarana penunjang demi kelancaran kegiatan akademik dan non-akademik (Atmia \& Aswar, 2018).

Laboratorium hidrolik merupakan salah satu fasilitas yang dimiliki oleh Sekolah Tinggi Penerbangan Indonesia tepatnya terdapat pada program studi teknik pesawat udara, fasilitas ini digunakan untuk membantu pelaksanaan proses belajar mengajar yang berkaitan dengan sistem pesawat udara yang menggunakan hidrolik beserta komponen-komponennya. Guna mendukung dan membantu peserta didik dalam praktik, keberadaan laboratorium hidrolik dan fasilitas pendukung lainnya harus tersedia agar kegiatan praktik dapat berjalan dengan lancar.

Di program studi teknik pesawat udara sendiri telah cukup tersedia alat - alat praktik dalam menunjang kegiatan belajar, tetapi masih diperlukan alat peraga praktek yang mengaplikasikan mekanisme pesawat sebenarnya. Maka dari itu sangat dibutuhkan suatu alat peraga yang dapatmenggambarkan sistem secara menyeluruh sehingga dapat diketahui mekanisme kerja sebuah sistem.

Speed brake atau airbrake sebagai salah satu sistem di pesawat yang memakai sisem hidrolik sebagai penggeraknya, seed brake merupakan jenis flight control surface yang digunakan pada pesawat untuk meningkatkan gaya hambat (drag) (Aerospace Design Engineers Guide Fifth Edition, 2003). Pada saat pesawat terbang meluncur, perlambatan atau gaya hambat pada flaps rendah sehingga dapat menggunakan speed brake untuk memperlambat kecepatan. Speedbrake dapat digunakan setiap saat, dan tidak mempengaruhi gaya angkat (lift) pesawat, dengan speedbrake dapat memperpendek jarak pengereman pesawat pada saat roda pendarat (landing gear) sudah menyentuh ground atau runway landasan.

Speed brake flaps tidak dapat dioperasikan pada saat pesawat sedang dalam keadaan take off configuration, ini dimaksudkan untuk sisi keselamatan, karena akan berbahaya penggunaanya pada pesawat sedang dalam keadaan full throttle dioperasikannya suatu speed brake flaps yang fungsi utamanya untuk memperlambat kecepatan pesawat saat akan melaksanakan pendaratan. Meskipun pengoperasian speed brake flaps sendiri dapat dilakukan setiap saat.

Dari penjelasan tersebut di atas, speed brakes digunakan sebagai perlambatan kecepatan untuk meningkatkan gaya hambat sehingga pesawat dapat melakukan pendekatan pendaratan. Mengacu pada kurikulum syllabusdi Prodi Teknik Pesawat Udara Kampus Sekolah Tinggi Penerbangan Indonesia, Curug-Tangerang AFM 08.12 mengenai :

"Fungsi dan sistem operasi flight pada boundary layer control, slat \& slot pada tipe fix and automatic spoiler dan speed brakes"

Penulis bermaksud untuk membuat permodelan alat peraga simulasi speed brake flaps yang terdapat pada pesawat terbang di Prodi Teknik Pesawat Udara Sekolah Tinggi Penerbangan Indonesia, dan mengenalkan sistim speed brake flaps yang terdapat pada pesawat 
terbang dan dapat pula memberikan gambaran secara umum mengenai sistim flight control mengenai speed brake flaps sehingga proses pengajaran dapat berhasil sesuai dengan tujuan dari syllabus yaitu siswa memiliki kemampuan untuk dapat memahami prinsip dasar dari struktur pesawat terbang serta memiliki kemampuan dasar melakukan perawatan, karena selama ini siswa hanya dapat membayangkan tidak pernah melihat secara langsung alat yang dipelajari. Maka perancang akan menyusun penelitian dengan judul: "RANCANGAN MODEL SPEED BRAKE FLAPS TIPE CLAMSHELL SEBAGAI ALAT PERAGADIPRODITEKNIKPESAWAT UDARA SEKOLAHTINGGI PENERBANGAN INDONESIA CURUG-TANGERANG".

Dari uraian Latar Belakang Masalah yang telah dijelaskan sebelumnya, maka perancang mencoba mengidentifikasikan beberapa masalah sebagai berikut :

a. Memberikan gambaran saat speed brake flaps tidak dapat berfungsi pada kondisi take off configuration.

b. Pengaruh ketersedian alat peraga speed brake flaps terhadap kurikulum syllabus AFM 08.12 terhadap proses pengajaran.

c. Memberikan gambaran secara umum mengenai sistim speed brake flaps dan mengenalkan bagaimana cara melakukan perawatannya.

d. Merancang sebuah speed brake flaps untuk mengetahui mekanisme kerjanya yang sesuai dengan pengoperasian di pesawat.

Berdasarkan Latar Belakang Masalah, dan Identifikasi sebelumnya, maka dapat dirumuskan bahwa masalah yang akan dibahas adalah sebagai berikut :

a. Bagaimana merancang sebuah sistim hidrolik dan sistim kelistrikan pada alat peraga speed brake flaps?

b. Bagaimana merancang sebuah panel yang dapat menunjukkan secara visual dari suatu pergerakan speed brake flaps?

c. Bagaimana memilih komponen sistim hidrolik dan sistim kelistrikan yang berkaitan dengan rancangan alat peraga speed brake flaps?

d. Bagaimana menghitung merancang alat peraga yang mensimulasikan pergerakan speed brake sesuai dengan pengoperasian?
Tujuan yang ingin dicapai dari perancangan alat peraga speed brake flaps tipe clamshell adalah sebagai berikut :

a. Mengetahui komponen apa saja yang digunakan untuk membuat sebuah panel speed brake flaps.

b. Menghitung gaya yang dibutuhkan pada sistim mekanikal.

c. Mengetahui bagamaina prinsip kerja dasar dan pengoperasian speed brake.

d. Mengetahui berapa daya yang dibutuhkan untuk mengoperasikan alat tersebut.

Speed Brake merupakan sebuah flap pada pesawat terbang untuk mengurangi kecepatan dalam persiapan pendaratan. Speed brake juga merupakan sebuah kontrol sistim yang membentang dari struktur pesawat terhadap aliran udara untuk menghasilkan gaya hambat dan memperlambat kecepatan pesawat.

Dalam dunia penerbangan, speed brake merupakan jenis flight control surface yang digunakan pada pesawat terbang untuk meningkatkan gaya hambat atau meningkatkan sudut pendekatan selama proses pendaratan. Speed brake paling awal dikenal dan dikembangkan pada tahun 1931 dan ditempatkan pada strut di sayap pesawat terbang. Tidak lama setelah itu, speed brake dikembangkan lagi di bagian trailing edge dan menjadi standar air brake pesawat terbang selama beberapa dekade.

Secara umum, speed brake dan spoiler merupakan jenis flight control yang fungsi nya serupa, yaitu untuk memperlambat kecepatan pesawat dengan meningkatkan gaya hambat. Speed brake dan spoiler dapat digunakan pada saat terbang dan pada saat di darat (ground).

Speed brake dikontrol oleh speed brake lever, speed brake lever memiliki dua posisi, yaitu : IN dan OUT. Maksudnya adalah pada saat lever pada posisi IN maka speed brake dalam kondisi belum membuka, sedangkan lever pada posisi OUT maka speed brake dalam kondisi membuka sehingga menghasilkan gaya hambat dan mengurangi kecepatan pesawat saat hendak melakukan pendaratan.

Sistim yang digunakan pada speed brake adalah sistim hidrolik yang digunakan untuk membuka dan menutup flap. Pada saat speed brake membuka ditunjukkan oleh lampu yang 
terletak di panel instrumentasi utama pada kokpit pesawat terbang.

Secara manual, speed brake dapat terbuka pada saat thrust lever berada pada posisi di bawah minimum take-off (MIN. T/O) dan kondisi thrust lever tidak berada dalam keadaan full throttle dan pada saat posisi roda pendarat pesawat sudah dalam keadaan turun (down-lock).

Pada pesawat Fokker 100 memiliki dua sistem yang independen, yaitu lift dumper dan speedbrake. Lift dumper serupa dengan spoiler, namun hanya dapat dioperasikan di ground saja. Pengoperasiannya dapat diperpanjang (extend) atau ditarik (retract) secara otomatis.

macam yaitu

Teori yang digunakan ada beberapa

1) Teori Fisika

a. Gaya Normal

Merupakan komponen yang tegak lurus terhadap permukaan. Sebuah kasus sederhana seperti sebuah benda yang diam di atas meja, gaya normal pada benda adalah sama, tetapi dalam arah yang berlawanan terjadi gaya gravitasi.

b. Sliding Friction

Merupakan gaya gesek terhadap gerakan meluncur (sliding) yang terjadi pada permukaan atas suatu objek. Berkaitan dengan itu, gesekan terjadi setelah benda telah ditetapkan dalam keadaan bergerak dan selalu kurang dari awal gesekan. Jumlah gaya gesek tergantung pada sifat suatu permukaan benda, permukaan yang mengalami pergeseran dan gaya normal di antara objek yang bergerak dan permukaan.

c. Kinematika Rotasi

Kinematika rotasi adalah pergerakan sebuah benda yang memiliki sumbu tetap sebagai acuannya, bergerak dalam lingkaran yang pusatnya terletak pada sebuah garis lurus yang disebut sumbu rotasi.

d. Trigonometri

Trigonometri sebagai suatu metode dalam perhitungan untuk menyelesaikan masalah yang berkaitan dengan perbandinganperbandingan pada bangun geometri, khususnya dalam bangun yang berbentuk segitiga. Pada prinsipnya trigonometri merupakan salah satu ilmu yang berhubungan dengan besar sudut, dimana bermanfaat untuk menghitung ketinggian suatu tempat tanpa mengukur secara langsung sehingga bersifat lebih praktis dan efisien.

2) Teori Mekanika Fluida
a. Hukum Pascal (Pascal Law's)
b. Persamaan Kontinuitas
c. Kerugian Gesekan (Friction Loss)
d. Persamaan Darcy-Weisbach

3) Teori Komponen Hidrolik

Komponenhidrolik yang terdapat pada rancangan alat peraga, yaitu sebagai berikut :

a. Tangki (Reservoir)

Memiliki fungsi menyediakan pasokan fluida ke sistim dengan menyimpan sejumlah cairan fluida yang dibutuhkan.

b. Pompa Hidrolik Tipe Gear (Gear Type Pump)

Pompa hidrolik berfungsi mendistribusikan fluida dari tangki ke sistim hidrolik sehingga menghasilkan tekanan fluida yang diperlukan.

c. Silinder Penggerak (Actuator)

Silinder penggerak (actuator) berfungsi sebagai pengubah tenaga hidrolik menjadi energi mekanik.

d. Katup Pengatur Arah (Directional Control Valve)

Digunakan Untuk mengatur arah aliran fluida di dalam rangkaian hidrolik.

e. Alat Pengukur Tekanan (Pressure Gauge) Digunakan untuk mengukur tekanan di dalam sistim hidrolik yang digunakan untuk mengoperasikan unit hidrolik. Alat pengukur tekananini menggunakan suatu prinsip bourdon tube dan susunan mekanikal untuk mengirimkan ekspansi dari tabung menuju indikator.

f. Hose

Hose digunakan dalam sistim tenaga fluida untuk menghubungkan komponenkomponen yang bergerak dengan komponen yang diam.

g. Konektor Saluran Hidrolik

Konektor yang digunakan dalam saluran hidrolik adalah elbow $90^{\circ}$ dan tee junction beserta nipple.

h. Cairan Hidrolik

Cairan hidrolik digunakan untuk menyalurkan dan mendistribusikan tenaga ke berbagai unit yang akan digerakkan. Cairan hidrolik mempunyai sifat dasar, diantaranya disebutkan pada Hukum 
Pascal, yang berbunyi : "Pada suatu zat cair yang diam, bila mendapat suatu tekanan, maka tekanan tersebut akan disalurkan ke segala arah sama besar" dan pada Hukum Bernoulli disebutkan bahwa : "Pada suatu zat cair yang bergerak, yang terletak di dalam suatu bejana atau tabung, maka percepatannya akan berbanding terbalik dengan tekanannya".

4) Teori Kelistrikan

Rancangan alat peraga simulasi speed brake menggunakan sistim kelistrikan sederhana untuk mempermudah mengkontrol membuka dan menutupnya speed brake flaps yang dengan mudah dapat dikontrol melalui suatu panel.

a. Daya Listrik

b. Teori Komponen Kelistrikan

c. Kontaktor

d. Pemutus Arus

\section{METODE}

Dalam penyusunan rancangan alat peraga speed brake flaps ini, maka metodologi perancangan yang perancang gunakan adalah sebagai berikut :

a. Metode Pustaka, menggunakan buku-buku literatur yang berhubungan atau dapat dijadikan referensi dalam penyelesaian rancangan alat peraga speed brake flaps ini.

b. Metode Eksperimen, melakukan percobaan terhadap hasil rancangan untuk mendapatkan data yang akurat.

\section{HASIL DAN PEMBAHASAN}

Rancangan alat peraga speed brake dibuat dengan tujuan untuk menunjukkan mekanisme kerja membuka (extend) dan menutup (retract) yang dioperasikan melalui sebuah panel sederhana dan digerakkan oleh silinder penggerak (actuator). Konsep dasar rancangan ini mengacu pada pengoperasian yang terdapat di pesawat Fokker-100 tetapi hanya prinsip dasarnya saja yang digunakan tidak menyeluruh pada pesawat tersebut

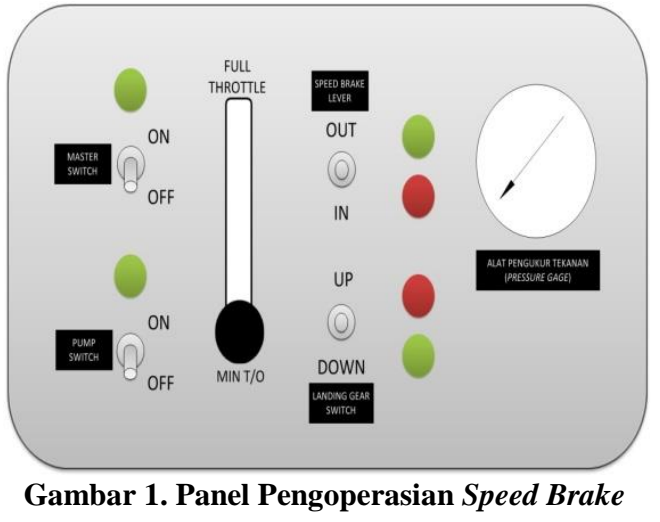

Gambar 1 diatas menunjukkan panel dari pengoperasian rancangan alat peraga speed brake menggunakan sumber listrik 220 $\mathrm{V}$ yang dirangkai dengan rangkaian listrik sederhanayang terdiri dari : Master Switch, Pump Switch, Throttle yang terdiri dari dua unit micro switch, Speed Brake Lever, Landing Gear Switch, Lampu Indikator dan Alat Pengukur Tekanan (Pressure Gage).

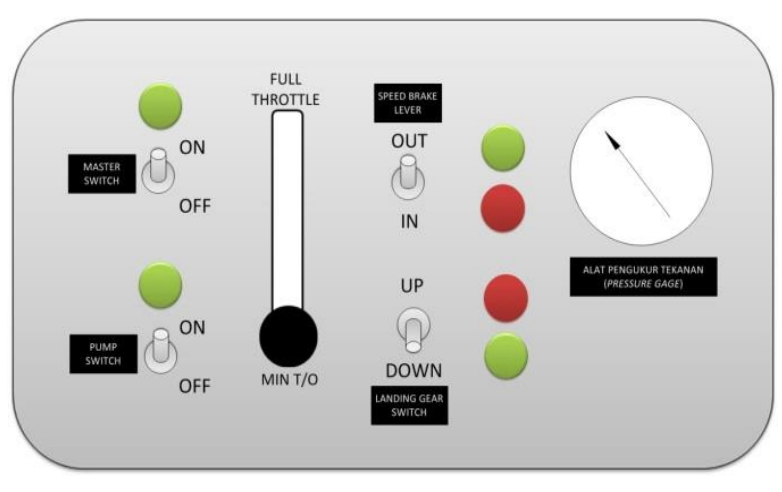

Gambar 2. Panel Posisi Speed Brake Pada Saat Terbuka

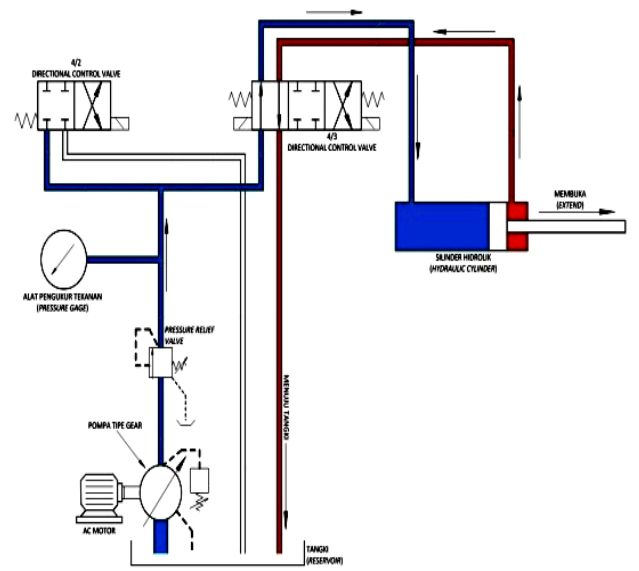

Gambar 3. Sistim Hidrolik Speed Brake Pada Saat Flaps Terbuka 
Pada gambar 2 menjelaskan posisi terbukanya speed brake flaps yang dikontrol melalui panel.Speed brake dapat beroperasi pada saat landing gear switch berada pada posisi DOWN yang ditunjukkan dengan lampu indikator berwarna hijau menyala dan Throttle berada pada posisi MIN T/O sesuai dengan AOM Fokker 100. Speed brake lever diarahkan ke posisi OUT, maka speed brake flaps akan terbuka.

Pada gambar 3 menjelaskan hidrolik sistim pada saat speed brake dalam keadaan terbuka. Telah dijelaskan sebelumnya, bahwa speed brake terbuka pada posisi landing gear switch dalam posisi DOWN, throttle berada pada posisi MIN T/O sesuai dengan AOM Fokker-100 dan speed brake lever berada pada posisi OUT. Aliran fluida mengalir dari tangki yang dihisap oleh pompa hidrolik melewati restriction check valve, pressure gage dan terbagi dua masuk ke dalam $4 / 2$ directional control valve dan $4 / 3$ directional control valve. 4/2 directional control valve berfungsi sebagai bypass apabila pompa hidrolik dalam keadaan berputar dan posisi speed brake lever dalam keadaan netral. Ini bertujuan agar tidak terjadi beban aliran fluida yang berlebihan pada 4/3 directional control valve. Aliran fluida yang menuju ke 4/3 directional control valve akan di arahkan masuk ke dalam port A pada silinder penggerak dan menggerakkan piston rod silinder penggerak sehingga flaps terbuka.

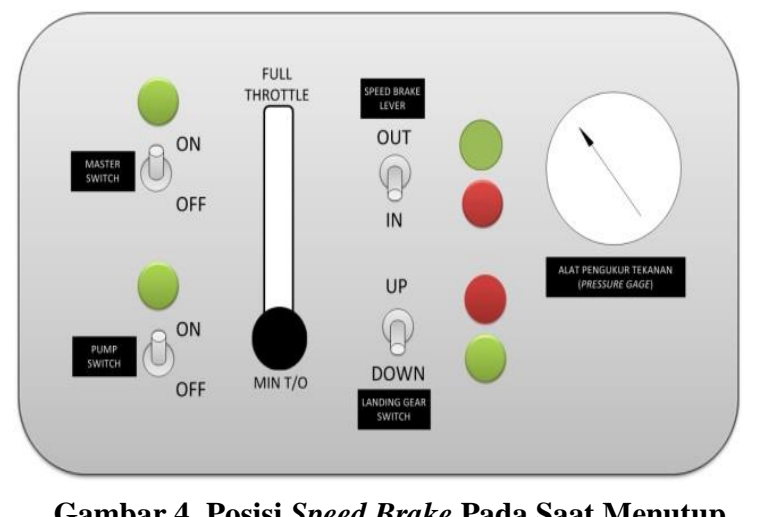

Pada gambar 4 menjelaskan posisi meutupnya speed brake flap yang dikontrol melalui panel.Speed brake dapat beroperasi pada saat landing gear switch berada pada posisi DOWN yang ditunjukkan dengan lampu indikator berwarna hijau menyala dan Throttle berada pada posisi MIN T/O sesuai dengan AOM Fokker 100. Speed brake lever diarahkan ke posisi IN, maka speed brake flaps akan tertutup.

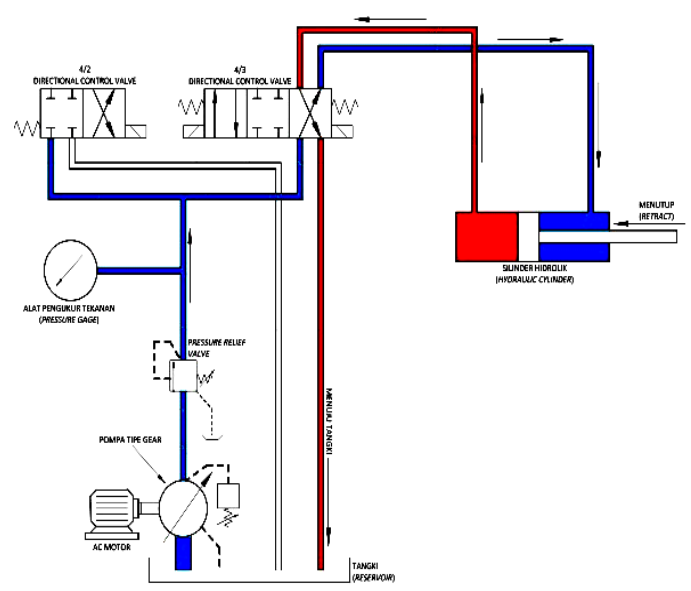

Gambar 5. Sistim Hidrolik Speed Brake Pada Flaps Tertutup

Pada gambar 5 menjelaskan hidrolik sistim pada saat speed brake dalam keadaan tertutup. Telah dijelaskan sebelumnya, bahwa speed brake terbuka pada posisi landing gear switch dalam posisi DOWN, throttle berada pada posisi MIN T/O sesuai dengan AOM Fokker-100 dan speed brake lever berada pada posisi IN.

Aliran fluida mengalir dari tangki yang dihisap oleh pompa hidrolik melewati pressure relief valve, pressure gage dan terbagi dua masuk ke dalam 4/2 directional control valve dan $4 / 3$ directional control valve. 4/2 directional control valve berfungsi sebagai bypass apabila pompa hidrolik dalam keadaan berputar dan posisi speed brake lever dalam keadaan netral. Ini bertujuan agar tidak terjadi beban aliran fluida yang berlebihan pada 4/3 directional control valve.

Aliran fluida yang menuju ke $4 / 3$ directional control valve akan di arahkan masuk ke dalam port B silinder penggerak dan menggerakkan piston rod silinder penggerak sehingga flaps tertutup. 


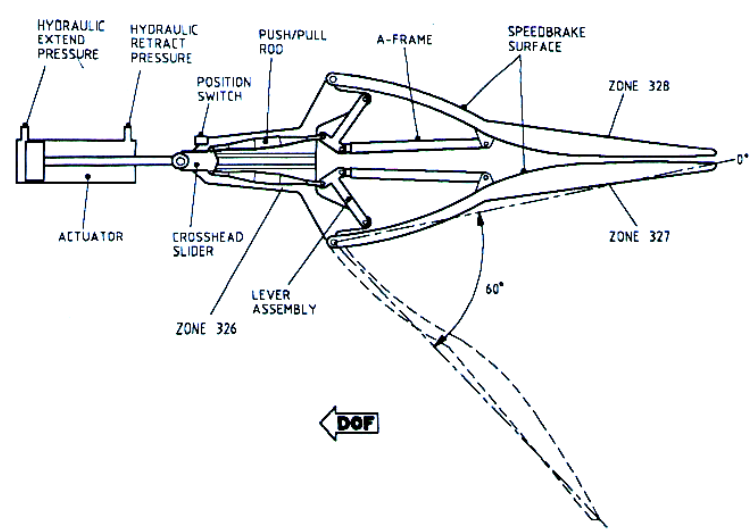

Gambar 6. Mekanikal Speed Brake

Rancangan alat peraga speed brake terdiri dari dua unit flaps, crosshead slider, push rod dan A-frame yang dibuat dengan bahan mild steel karena bahan tersebut memiliki karakteristik ringan, kuat dan mudah dibentuk, bentuk dari sistim mekanikal rancangan alat peraga speed brake flaps penulis buat sesuai dengan sistim mekanikal speed brake yang terdapat di pesawat Fokker-100, dapat dilihat pada gambar 6 diatas. Dimensi dari sistim mekanikal yang penulis buat, diskalakan agar dapat disesuaikan dengan meja rancangan yang penulis rancang.

\section{KESIMPULAN}

a. Komponen yang digunakan untuk membuat panel rancangan alat peraga speed brake, yaitu enam buah lampu indikator, empat buah toggle switch, dan satu buah pressure gauge.

b. Gaya yang dibutuhkan setelah melalui proses perhitungan adalah 160,83 lbf.

c. Dalam pembuatan rancangan alat peraga speed brake tentunya penulis mengacu pada prosedur pengoperasian dasar yang terdapat di pesawat Fokker-100 tetapi tidak menyeluruh. Dalam pengoperasian tersebut, speed brake tidak dapat dioperasikan pada saat roda pendarat pesawat belum dalam keadaan down \& lock dan juga speed brake tidak dapat dioperasikan pada saat throttle dalam keadaan FULL THROTTLE. Sehingga penulis merancang sebuah panel yang berfungsi untuk mempermudah dalam mengkontrol speed brake flaps.

d. Ketiga rangkaian pada rancangan alat peraga dapat beroperasi dengan baik pada daya yang dibutuhkan sebesar 766 Watt.

Hasil penelitian ini menyarankan:

1) Perlu memperhitungkan daya yang dibutuhkan pada rancangan, sehingga dapat digunakan secara efisien, baik pada listrik rumahan, menengah maupun kelas atas.

2) Untuk perancangan selanjutnya, perlu menambahkan filter agar partikelpartikel kotoran maupun debu yang terdapat pada cairan fluida yang disimpan di dalam tangki tidak ikut masuk ke dalam sistim yang dapat menghambat laju aliran fluida.

3) Motor listrik yang digunakan terlalu besar dimensinya, untuk selanjutnya perlu mengganti motor listrik dengan dimensi yang kecil agar rancangan alat peraga tidak terlalu berat sehingga mudah untuk dipindahkan dari satu tempat ke tempat lainnya.

\section{DAFTAR PUSTAKA}

Aircraft Operation Manual (AOM) Fokker-100

American Institute of Aeronautics and Astronautics. (2003). Aerospace Design Engineers Guide Fifth Edition. Virginia USA.

Andrew Parr. (2006). Hydraulic and Pneumatics a Technicians and Engineer's Guide Second Edition. Oxford U.K.

Atmia, K., \& Aswar A., M. (2018). Simulasi Marker Beacon berbasis Mikrocontroller di Akademi Teknik dan Keselamatan Penerbangan Makassar. Airman: Jurnal Teknik Dan Keselamatan Transportasi, 1(1), 6-10. https://doi.org/10.46509/ajtk.v1i1.3 
Britannica Online Encyclopedia, http://www.britannica.com/EBchecked/to pic/11014/airplane?anchor=ref527978\#,

Dale Crane. (1975). Aircraft Hydraulic System. Basin, Wyoming: AMPI.

Digital-Aviation Document, FOKKER 70/100 Boeing Migration Guide

Erlangga. (1987). Fisika Jilid 1 Edisi Ketiga. Jakarta.

Federal Aviation Administration. Airframe Handbook. Oklahoma.

Federal Aviation Administration. (2008). Aviation Maintenance Technician Handbook - General. Oklahoma.

Franklin D. Yeaple. (1966). Hydraulic and Pneumatic Power and Control. New York: McGraw-Hill Book Company.

John Bird. (2002). Electrical Circuit Theory and Technology Third Edition. Elsevier: Great Britain.

Maintenance Manual (MM) Fokker-100

M. Galal Rabie. (2009). Fluid Power Engineering. Mc-Graw Hill USA.

Peter J. Chapple. (2003). Principle of Hydraulic System Design First Edition. Oxford U.K.

Ranald V. Giles, Jack B. Evett \& Cheng Liu. (1993). Schaum's Outline of Theory and Problems of Fluid Mechanics and Hydraulics Third Edition. Mc-Graww Hill.

Ravi Doddanavar \& Andries Barnard. (2005). Practical Hydraulic Systems Operation and Troubleshooting for Engineering \& Technicians. Newnes.

R.S Khurmi \& J.K Gupta. (2005). A Textbook of Machine Design. Eurasia Publishing House, New Delhi.

Stephen L. Herman. (2010). $6^{\text {Th }}$ Edition Industrial Motor Control. Delmar Cengage Learning, USA. 